\title{
Efficiency of Sequence Characterized Amplified Region Markers for Selecting Non-Astringent Persimmon (Diospyros kaki Thunb.)
}

\author{
Yeo-Ok Park ${ }^{1 *}$, Hee-Jeong Jae ${ }^{2}$, Ji-Young Shon ${ }^{1}$, Seong-Tae Choi ${ }^{1}$, Sung-Chul Kim ${ }^{1}$, Yong-Cho Cho ${ }^{2}$, \\ Kwang-Pyo Hong' ${ }^{2}$, Younghoon Park ${ }^{3}$ \\ ${ }^{1}$ Sweet Persimmon Research Institute, Gimhae 50871, Korea \\ ${ }^{2}$ Gyeongsangnam-do Agricultural Research and Extension Services, Jinju 52733, Korea \\ ${ }^{3}$ Department of Horticultural Bioscience, Pusan National University, Miryang 50463, Korea
}

\begin{abstract}
Persimmon (Diospyros kaki Thunb.) is classified into four types based on the fruit traits, astringency and flesh color. Of the four types, the pollination-constant non-astringent (PCNA) fruit is typically most desirable for consumption. In the present study, we used five sequence characterized amplified region (SCAR) markers associated with astringency in persimmon fruit, namely E4/E9r, E4/A2r, 7H9F/AST-R, AST-F/AST-R, and AST-F/PCNA-F/5R3R, to improve the efficiency of PCNA-type persimmon breeding via marker-assisted selection (MAS). A total of 84 cultivars of the four types and their segregating F1 progeny were used to evaluate the association of SCAR markers with the fruit astringency phenotype. Polymerase chain reaction evaluation of each SCAR marker showed that E4/E9r combined with AST-F/PCNA-F/5R3R was appropriate for selecting the ast allele responsible for PCNA-type fruit, as the phenotype-genotype match percentages of these two markers were $94 \%$ and $99 \%$, respectively. This MAS was verified by the successful use of AST-F/PCNA-F/5R3R to select 107 PCNA-type individuals from 609 F1 hybrid progeny derived from various crosses.
\end{abstract}

Keywords Marker-assisted selection, Persimmon, Pollination-constant non-astringent, Sequence characterized amplified region

\section{INTRODUCTION}

Persimmon (Diospyros kaki Thunb.) is a perennial woody plant of the genus Diospyros and is a member of the order Ebenales. The origin of this species traces back to East Asia and it has been cultivated since the pre-Christ era (Yonemori et al. 2000). Most persimmon cultivars are hexaploid $(2 \mathrm{n}=6 \mathrm{x}=90)$, although some are akaryotic nonaploid $(2 \mathrm{n}=9 \mathrm{x}=135)$ (Zhuang et al. 1990; Tamura et al. 1998). Persimmon is classified as one of the four types based on the presence or absence of astringency in the fruit and the darkening of flesh color around seeds following pollination. These four types are referred to as pollination-constant non-astringent (PCNA), pollination variant non-astringent (PVNA), pollination variant astringent (PVA), and pollination-constant astringent (PCA) (Yamada 1993). Of the four types, PCNA is most preferred by consumers due to its low astringency and absence of dark flesh in ripe fruit. The first PCNA cultivar in Japan known to the public was 'Gosho', which has been broadly cultivated for 200 years (Kikuchi 1948). Various PCNA cultivars have since been created using 'Gosho' by natural hybridizations or the discovery and isolation of bud mutations, and cultivated with limited regional distribution. These cultivars share a similar phenotype and genotype, and therefore display high levels of inbreeding depression when further hybridization is performed among the cultivars (Yamada 2005).

In order to prevent genetic erosion and improve genetic diversity, introgression breeding is needed to introduce background traits from non-PCNA into PCNA cultivars. However, PCNA is determined by the homozygous presence of the single recessive allele ast, and thus long breeding periods are required due to the low probability of

Received August 22, 2016; Revised August 24, 2016; Accepted August 25, 2016; Published August 31, 2016

*Corresponding author Yeo-Ok Park, cjsw98@korea.kr, Tel: +82-55-254-1554, Fax: +82-55-254-1559 
selecting for PCNA plants (Ikeda et al. 1985; Yonemori et al. 2000). Marker-assisted selection (MAS) using ast-linked DNA markers may improve the efficiency of breeding programs as PCNA plants could be selected at the seedling stage. Most reported sequence characterized amplified region (SCAR) markers are limited in their use as they detect only the dominant Ast allele; therefore, a heterozygous individual (Ast/ast) cannot be discriminated (Kanzaki et al. 2001; Yonemori et al. 2003; Kanzaki et al. 2008; Kanzaki et al. 2009; Park et al. 2013). However, Kanzaki et al. (2010) has developed a set of SCARs that are tightly linked to ast allele and can thus select for PCNA plants. Compared to other DNA markers, such as random amplified polymorphic DNA (RAPD) or amplified fragment length polymorphism (AFLP), SCARs are advantageous in that they are allele-specific and highly reproducible. The current set of PCNA SCAR markers also aid detection of both Ast and ast alleles and genotype heterozygous plants.

It is difficult to breed novel sweet persimmon cultivars because it is time consuming and requires large field space. These limiting factors may be overcome in future breeding programs by increasing selection efficiency through MAS. The objective of this study was to analyze SCAR markers reported by Kanzaki et al. (2010) in diverse cultivars and populations from different crosses in Korea, in order to evaluate the suitability of these markers for use in PCNA cultivar MAS.

\section{MATERIALS AND METHODS}

\section{Plants materials and DNA extraction}

Persimmon accessions included 84 cultivars and breeding lines: 31 of PCNA type, 21 of PVNA type, 11 of PVA type, and 21 of PCA type (Table 1). Also analyzed were 609

Table 1. List of persimmon cultivars and breeding lines (Diospyros kaki Thunb.) used in this study and their resulting ast locus marker genotyping.

\begin{tabular}{|c|c|c|c|c|c|}
\hline \multirow{2}{*}{ No. } & \multirow{2}{*}{ Accession } & \multirow{2}{*}{ Type $^{\text {z) }}$} & \multirow{2}{*}{ Origin } & \multicolumn{2}{|c|}{ SCARs marker ${ }^{\mathrm{y})}$} \\
\hline & & & & E4/E9r $(2,200 \mathrm{bp})$ & AST-F/PCNA-F/5R3R (220 bp) \\
\hline \multicolumn{6}{|c|}{ Cultivars } \\
\hline 1 & Maegawajiro & PCNA & Japan & - & - \\
\hline 2 & Fujiwaragosho & PCNA & Japan & - & - \\
\hline 3 & Jiro & PCNA & Japan & - & - \\
\hline 4 & Midai & PCNA & Japan & - & - \\
\hline 5 & Mammoth & PCNA & Japan & - & - \\
\hline 6 & Sunami & PCNA & Japan & - & - \\
\hline 7 & Matsumotowase-Fuyu & PCNA & Japan & - & - \\
\hline 8 & Fuyu & PCNA & Japan & - & - \\
\hline 9 & Ichikikeijiro & PCNA & Japan & - & - \\
\hline 10 & Gosho & PCNA & Japan & - & - \\
\hline 11 & Suruga & PCNA & Japan & - & - \\
\hline 12 & Okugosho & PCNA & Japan & - & - \\
\hline 13 & Yaizuwasejiro & PCNA & Japan & - & - \\
\hline 14 & Mikado & PCNA & Japan & - & - \\
\hline 15 & Tenjingosho & PCNA & Japan & - & - \\
\hline 16 & Ro-19 & PCNA & Japan & - & - \\
\hline 17 & Hanagosho & PCNA & Japan & - & - \\
\hline 18 & WakasugikeiJiro & PCNA & Japan & - & - \\
\hline 19 & Daeandangam & PCNA & Korea & - & - \\
\hline 20 & IsaHaya & PCNA & Japan & - & - \\
\hline 21 & Wakakishiro & PCNA & Japan & - & - \\
\hline 22 & kastusa & PCNA & Japan & - & - \\
\hline 23 & Youhou & PCNA & Japan & - & - \\
\hline 24 & Izu & PCNA & Japan & - & - \\
\hline 25 & Uenishiwase & PCNA & Japan & - & - \\
\hline 26 & Shinsyu & PCNA & Japan & - & - \\
\hline 27 & Kinshu & PCNA & Japan & - & - \\
\hline 28 & Taurei & PCNA & Japan & - & - \\
\hline
\end{tabular}


Table 1. Continued.

\begin{tabular}{|c|c|c|c|c|c|}
\hline \multirow{2}{*}{ No. } & \multirow{2}{*}{ Accession } & \multirow{2}{*}{ Type $^{\text {z) }}$} & \multirow{2}{*}{ Origin } & \multicolumn{2}{|c|}{ SCARs marker ${ }^{\mathrm{y})}$} \\
\hline & & & & E4/E9r $(2,200 \mathrm{bp})$ & AST-F/PCNA-F/5R3R (220 bp) \\
\hline 29 & Dongwon1 & PCNA & Korea & - & - \\
\hline 30 & Dongwon2 & PCNA & Korea & - & - \\
\hline 31 & Dongwon3 & PCNA & Korea & - & - \\
\hline 32 & Toyouichi & PVNA & Japan & + & + \\
\hline 33 & Johongsi & PVNA & Korea & + & + \\
\hline 34 & Nishimurawase & PVNA & Japan & + & + \\
\hline 35 & Migatanigosho & PVNA & Japan & + & + \\
\hline 36 & Haschiuri & PVNA & Japan & + & + \\
\hline 37 & Amahyakume & PVNA & Japan & + & + \\
\hline 38 & Koharu & PVNA & Japan & + & + \\
\hline 39 & Kyara & PVNA & Japan & + & + \\
\hline 40 & Zenjimaru & PVNA & Japan & + & + \\
\hline 41 & Sanggokuitsy & PVNA & Japan & + & + \\
\hline 42 & Akagaki & PVNA & Japan & + & + \\
\hline 43 & Tenrubou & PVNA & Japan & + & + \\
\hline 44 & Toyoga & PVNA & Japan & + & + \\
\hline 45 & Niitsugaki & PVNA & Japan & + & + \\
\hline 46 & Mizushima & PVNA & Japan & + & + \\
\hline 47 & Shougatsu & PVNA & Japan & + & + \\
\hline 48 & Baojiaozi & PVNA & Japan & + & + \\
\hline 49 & Sae-Fuji & PVNA & Japan & + & + \\
\hline 50 & Kaki Tipo & PVNA & Italy & + & - \\
\hline 51 & Wasesaijo & PCA & Japan & - & + \\
\hline 52 & Goseung-Tabaegam & PCA & Japan & - & + \\
\hline 53 & O-miyawase & PCA & Japan & + & + \\
\hline 54 & Sancheong-Danseongsi & PCA & Korea & + & + \\
\hline 55 & Sancheong-Kojongsi & PCA & Korea & + & + \\
\hline 56 & Sancheong-Kodongsi & PCA & Korea & + & + \\
\hline 57 & Yeongju-Kodongsi & PCA & Korea & + & + \\
\hline 58 & Saijo & PCA & Japan & + & + \\
\hline 59 & Yeongdeong-Weolhasi & PCA & Korea & + & + \\
\hline 60 & Yeuseung-Sagoksi & PCA & Korea & + & + \\
\hline 61 & Myeongju-Kojongsi & PCA & Korea & + & + \\
\hline 62 & Cheongdo-Bansi & PCA & Korea & + & + \\
\hline 63 & Gyeongsan-Bansi & PCA & Korea & - & + \\
\hline 64 & Haman-Mulgam & PCA & Korea & + & + \\
\hline 65 & Haman-Bansi & PCA & Korea & + & + \\
\hline 66 & Goesan-Durigam & PCA & Korea & + & + \\
\hline 67 & Sangju-Dungsi & PCA & Korea & + & + \\
\hline 68 & Eunpungjunsi & PCA & Korea & + & + \\
\hline 69 & Sureo & PCA & Korea & + & + \\
\hline 70 & Mopanshi & PCA & China & + & + \\
\hline 71 & Black persimmon & PCA & China & + & + \\
\hline 72 & Tonewase & PVA & Japan & + & + \\
\hline 73 & Sugitawase & PVA & Japan & + & + \\
\hline 74 & Superhiratanenashi & PVA & Japan & + & + \\
\hline 75 & O-tanenashi & PVA & Japan & + & + \\
\hline 76 & Hiratanenashi & PVA & Japan & - & + \\
\hline 77 & Damopan & PVA & Japan & + & + \\
\hline 78 & Wasezizya & PVA & Japan & - & + \\
\hline 79 & Atago & PVA & Japan & + & + \\
\hline 80 & Hachiya & PVA & Japan & + & + \\
\hline 81 & Yaoki & PVA & Japan & + & + \\
\hline 82 & Rojo Brillante & PVA & Spain & + & + \\
\hline \multicolumn{6}{|c|}{ Breeding lines } \\
\hline 83 & Jamisi & PVNA & Korea & + & + \\
\hline 84 & Migamjosaeng & PVNA & Korea & + & + \\
\hline
\end{tabular}

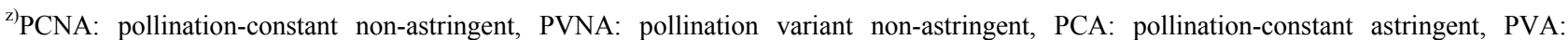
pollination variant astringent.

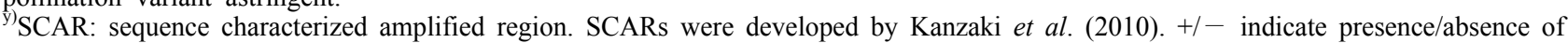
SCAR polymerase chain reaction products, specific for the $A S T$ locus, respectively. 
progeny plants derived from diverse crosses performed 2007 to 2012 between PCNA and non-PCNA cultivars at the breeding field of the Sweet Persimmon Research Institute (SPRI, Gimhae, Korea) (Table 2). Between 2009 and 2012, young leaf tissue was collected for DNA extraction and SCAR marker genotyping when two to three true leaves were fully expanded after foliation stage (between the end of April to May prior to flowering).

Table 2. Results of marker-assisted selection for pollination constant non-astringent (PCNA) persimmon plants (Diospyros kaki Thunb.) from various cross combinations using AST-F/PCNA-F/5R3R marker specific for the ast allele.

\begin{tabular}{|c|c|c|c|}
\hline Test year & Cross combination & Total & No. selected PCNA candidates \\
\hline \multirow[t]{9}{*}{2010} & Youhou $\times$ Taishu & 3 & 2 \\
\hline & Hachiya $\times$ Taishu & 18 & 6 \\
\hline & Maegawajiro $\times$ Taishu & 13 & 12 \\
\hline & Sunami $\times$ Taishu & 7 & 6 \\
\hline & Jamisi $\times$ Taishu & 8 & 4 \\
\hline & Uenishiwase $\times$ Tiashu & 3 & 0 \\
\hline & Jamisi $\times$ Sae-Fuji & 7 & 0 \\
\hline & Sae-Fuji $\times$ Taishu & 10 & 0 \\
\hline & Youhou $\times$ Sae-Fuji & 1 & 0 \\
\hline \multirow[t]{23}{*}{2011} & Izu $\times 95$ (line) & 33 & 4 \\
\hline & Maegawajiro $\times$ Taish & 39 & 27 \\
\hline & Youhou $\times$ Taish & 31 & 8 \\
\hline & Fuyu $\times$ Taishu & 3 & 3 \\
\hline & Sunami $\times$ Taishu & 27 & 8 \\
\hline & Migamjosaeng $\times$ Taishu & 58 & 4 \\
\hline & Jamisi $\times$ Taishu & 23 & 2 \\
\hline & Uenishiwase $\times$ Taishu & 12 & 9 \\
\hline & Uenishiwase $\times$ Kinshu & 5 & 3 \\
\hline & Migamjosaeng × 3-5 (line) & 27 & 0 \\
\hline & Jamisi × 3-5 (line) & 70 & 0 \\
\hline & Migamjosaeng $\times$ Sae-Fuji & 84 & 0 \\
\hline & Migamjosaeng $\times$ Kinshu & 4 & 0 \\
\hline & Migamjosaeng $\times$ Taishu & 6 & 1 \\
\hline & Uenishiwase $\times$ 3-5 (line) & 19 & 0 \\
\hline & Hachiya $\times$ Taishu & 9 & 0 \\
\hline & Jamisi $\times$ Sae-Fuji & 9 & 0 \\
\hline & Taishu $\times$ Sae-Fuji & 13 & 0 \\
\hline & Kinshu $\times$ Taishu & 1 & 0 \\
\hline & Youhou $\times$ Sae-Fuji & 1 & 1 \\
\hline & 3-5 (line) $\times$ Taishu & 6 & 0 \\
\hline & Cheongdo-Bansi $\times$ Taishu & 17 & 0 \\
\hline & Gillya × 96 (line) & 1 & 0 \\
\hline \multirow{12}{*}{2012} & Uenishiwase $\times 3-5$ (line) & 2 & 1 \\
\hline & Jamisi $\times$ Taishu & 2 & 1 \\
\hline & Migamjosaeng $\times$ Taishu A & 5 & 1 \\
\hline & Fuyu $\times$ Taishu & 2 & 2 \\
\hline & Maegawajiro $\times$ Taishu & 2 & 2 \\
\hline & Migamjosaeng $\times$ Sae-Fuji & 2 & 0 \\
\hline & Nishimurawase $\times 3-5$ (line) & 1 & 0 \\
\hline & Dongwon $3 \times 60$ & 17 & 0 \\
\hline & Uenishiwase $\times$ Kinshu & 1 & 0 \\
\hline & Migamjosaeng $\times$ Taishu & 1 & 0 \\
\hline & Jamisi $\times 3-5$ (line $)$ & 5 & 0 \\
\hline & Hachiya $\times$ Taishu & 1 & 0 \\
\hline Total & & 609 & 107 \\
\hline
\end{tabular}


Collected leaf samples were stored at $-80^{\circ} \mathrm{C}$ until further use, and ground under liquid nitrogen before DNA extraction. Genomic DNA were extracted from $1 \mathrm{~g}$ ground tissue using a Plant Genomic DNA isolation kit (Core-Bio, Seoul, Korea), and quantified using a spectrophotometer (UV-2450; Shimadzu, Tokyo, Japan or Pico200; Picodrop, Hinxton, England). DNA samples used for polymerase chain reaction (PCR) templates were diluted to $20 \mathrm{ng} / \mu 1$.

\section{SCAR marker genotyping}

SCAR markers developed by Kanzaki et al. (2010) (Table 3) were evaluated for their association with the PCNA type. PCRs of $20 \mu \mathrm{l}$ total volume were prepared by mixing 10 pmole forward and reverse primer (Table 3 ) with $4 \mu \mathrm{l}$ AccuPower PCR PreMix (Bioneer, Daejeon, Korea) containing $0.2 \mathrm{mM}$ dNTPs, $1 \mathrm{U}$ Taq DNA polymerase, and $2 \mu 110 \times$ reaction buffer. PCR was conducted using a PCR cycler (Biometra, Gottingen, Germany) with the following conditions: for markers $\mathrm{E} 4 / \mathrm{E} 9 \mathrm{r}$ and $\mathrm{E} 4 / \mathrm{A} 2 \mathrm{r}, 30$ seconds at $94^{\circ} \mathrm{C}, 30$ cycles of 1 minute at $94^{\circ} \mathrm{C}, 1$ minute at $59^{\circ} \mathrm{C}$, and 4 minutes (E4/E9r) or 2 minutes (E4/A2r) at $72^{\circ} \mathrm{C}$, and a final 7 minutes (E4/E9r) or 4 minutes (E4/A2r) extension at $72^{\circ} \mathrm{C}$; for markers $7 \mathrm{H} 9 \mathrm{~F} / \mathrm{AST}-\mathrm{R}$ and AST-F/AST-R, 30 seconds at $96^{\circ} \mathrm{C}, 30$ cycles of 10 seconds at $96^{\circ} \mathrm{C}, 30$ seconds at $57^{\circ} \mathrm{C}$ (7H9F/AST-R) or $55^{\circ} \mathrm{C}$ (AST-F/AST-R), and 30 seconds at $72^{\circ} \mathrm{C}$, and a final 1 minutes extension at $72^{\circ} \mathrm{C}$; for marker PCNA-F/AST-F/5R3R, 30 seconds at $96^{\circ} \mathrm{C}, 35$ cycles of 10 seconds at $96^{\circ} \mathrm{C}, 30$ seconds at $53^{\circ} \mathrm{C}$, and 30 seconds at $72^{\circ} \mathrm{C}$, and a final 7 minutes extension at $72^{\circ} \mathrm{C}$.

PCR products were separated by electrophoresis on a $2 \%$ agarose gel (Bioshop Biotechnology, Burlington, ON, Canada) with the addition of $\operatorname{RedSafe}^{\mathrm{TM}}$ (Intron, Seongnam, Korea) and using $1 \times$ Tris-borate-EDTA buffer. Gel images visualized using a Gel Documentation System (Bio-Rad, California, CA, USA).

\section{RESULTS}

\section{Evaluation of the SCAR markers using F1 cultivars}

Five SCAR markers using different primer combinations (Table 3) were evaluated for two F1 cultivars 'Jamisi' (PVNA) and 'Migamjosaeng' (PVNA) that were developed from a cross performed between 'Matsumotowase-Fuyu' (PCNA) and 'Nishimurawase' (PVNA) and F1 progeny plants isolated from a cross between 'Jamisi' and 'Taishu' (PCNA) (Fig. 1). For E4/E9r, a 4.6-kb band specific for the ast allele (PCNA) and a 2.2-kb band specific for the Ast allele (non-PCNA) were PCR amplified from 'Matsumotowase-Fuyu' and 'Nishimurawase', respectively, while both PCR products representing a heterozygous Ast/ast genotype were amplified from 'Jamisi' and 'Migamjosaeng'. For F1 progeny plants resulting from a cross performed between 'Jamisi' and 'Taishu', the E4/E9r PCR product specific for the ast allele

Table 3. Polymerase chain reaction primer information for sequence characterized amplified region markers used in this study for selecting pollination-constant non-astringent (PCNA) persimmon plants (Diospyros kaki Thunb.).

\begin{tabular}{llcc}
\hline \hline \multicolumn{1}{c}{ Marker name } & \multicolumn{1}{c}{ Sequence $\left(5^{\mathrm{z}} \rightarrow 3^{\prime}\right)$} & Temperature $\left({ }^{\circ} \mathrm{C}\right)$ & Product size $(\mathrm{bp})$ \\
\hline E4/E9r & E: CCCACTTACCAAACTAGGCTTCCAACACAAG G & 66.7 & 2,200 \\
& E9r: GCTTAGTCAGCTTAGCCACGCCATTC & 64.8 & \\
E4/A2r & E4: CCCACTTACCAAACTAGGCTTCCAACACAAG & 66.7 & 2,000 \\
& A2r: CTTGTAGTGAATTAACGGATATGGTG & 55 & \\
7H9F/AST-R & 7H9F: CAATCACTCATCTCACTTGCAC & 51.9 & 410 \\
& AST-R: CCCCTCATGCTTTGCATACTTAATG & 59.6 & \\
AST-F/AST-R & AST-F: GTTGCATCGCATAGCGGGTTTGAGG & 67.7 & \multirow{2}{*}{190} \\
& AST-R: CCCCTCATGCTTTGCATACTTAATG & 59.6 & \\
AST-F/PCNA-F/5R3R & PCNA-F: CCCCTCAGTGGCAGTGCTGC & 62.4 & 350 \\
& AST-F: GTTGCATCGCATAGCGGGTTTGAGG & 67.7 & 220 \\
& 5R3R: GAAACACTCATCCGGAGACTTC & 54 & \\
\hline
\end{tabular}

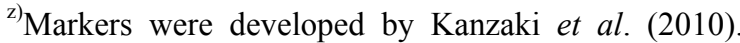


was amplified from two plants, but PCR products specific for both ast and Ast alleles were amplified from another six plants (Fig. 1A). Meanwhile, no E4/A2r PCR product was amplified from these plants (Fig. 1B).

7H9F/AST-R and AST-F/AST-R amplified 410-bp and 190-bp PCR products, respectively, from non-PCNA plants only. No PCR product was amplified from PCNA cultivars and PCR products specific for the Ast allele were amplified from both 'Jamisi' and 'Migamjosaeng' (Fig. 1C, D). AST-F/PCNA-F/5R3R produced a 350-bp PCR product specific for the ast allele from 'Matsumotowase-Fuyu' (PCNA) and a 220-bp product specific for the Ast allele from 'Nishimurawase' (PVNA), while both PCR products representing a heterozygous Ast/ast genotype were amplified from eight F1 progeny resulting from the cross between 'Jamisi' and 'Taishu' (Fig. 1E). These SCAR marker genotyping results indicated that, aside from E4/A2r, all markers were associated with specific phenotypes for 'Matsumotowase-Fuyu' and 'Nishimurawase', and their F1 cultivars 'Jamisi' and 'Migamjosaeng'. In addition, the
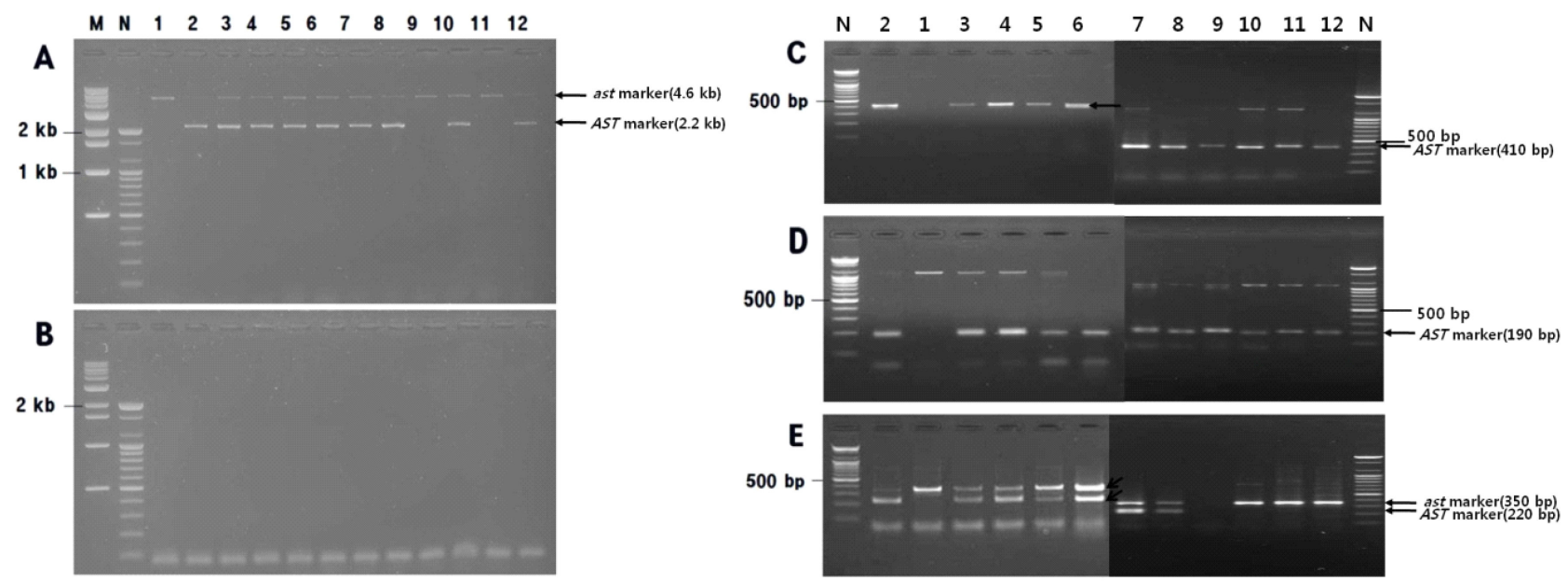

Fig. 1. Agarose gel image showing segregation of E4/E9r (A) and E4/A2r (B) marker in 10 offspring of 'MatsumotowaseFuyu' $\times$ 'Nishimurawase', 7H9F/AST-R (C) and AST-F/AST-R (D) in the progeny from 'Matsumotowase-Fuyu' $\times$ 'Nishimurawase', and multiplex polymerase chain reaction (PCR) (E) by the primer pair AST-F/PCNA-F/5R3R, amplified fragments using primer pair.

$\mathrm{M}$ : Kb ladder size marker, N: 100-bp ladder size marker, 1: 'Matsumotowase-Fuyu', 2: 'Nishimurawase', 3: 'Jamisi', 4: 'Migamjosaeng', 5-12: progenies from 'Jamisi' $\times$ 'Taishu'. For E4/A2r (B), no PCR band was amplified from several cultivars and their offspring.

Table 4. Pattern of polymerase chain reaction product formation of sequence characterized amplified region (SCAR) markers for selecting PCNA persimmon plants (Diospyros kaki Thunb.) observed from $\mathrm{F}_{1}$ seedlings derived from different cross combinations.

\begin{tabular}{|c|c|c|c|c|c|c|c|c|}
\hline \multirow{2}{*}{ Marker } & \multicolumn{8}{|c|}{ (Cross combination ${ }^{\text {z) }}$} \\
\hline & $\mathrm{J} \times \mathrm{T}$ & $\mathrm{J} \times \mathrm{S}$ & $\mathrm{H} \times \mathrm{T}$ & $\mathrm{Y} \times \mathrm{T}$ & $\mathrm{Y} \times \mathrm{S}$ & $\mathrm{C} \times \mathrm{T}$ & $\mathrm{I} \times \mathrm{T}$ & $\mathrm{Su} \times \mathrm{T}$ \\
\hline $\mathrm{E} 4 / \mathrm{E} 9 \mathrm{r}$ & $++^{\mathrm{y})}$ & + & + & + & + & + & + & + \\
\hline $\mathrm{E} 4 / \mathrm{A} 2 \mathrm{r}$ & - & - & - & - & - & - & - & - \\
\hline 7H9F/AST-R & + & + & + & + & + & + & + & + \\
\hline AST-F/AST-R & + & + & + & + & + & + & + & + \\
\hline AST-F/PCNA-F/5R3R & + & + & + & + & + & + & + & + \\
\hline
\end{tabular}

${ }^{2)}$ J: 'Jamishi' (PVNA), T: 'Taishu' (PCNA), S: 'Sae-Fuji' (PVNA), H: 'Hachiya' (PVNA), Y: 'Youhou' (PCNA), C: 'Cheongdo-Bansi' (PCA), I: 'Ichikikeijiro' (PCNA), Su: 'Sunami’ (PCNA).

${ }^{y}+$ and - indicate presence and absence of the SCAR bands, respectively.

PVNA: pollination variant non-astringent, PCNA: pollination-constant non-astringent, PCA: pollination-constant astringent. 
use of the E4/E9r SCAR marker enabled two out of eight progeny plants resulting from a cross between 'Jamisi' and 'Taishu' to be classified as PCNA, thereby demonstrating the underlying MAS principle.

\section{Evaluation of the SCAR marker using cross populations}

F1 progeny populations derived from eight crosses between 'Jamisi' (PVNA) and 'Taishu' (PCNA) were analyzed using the SCAR markers. E4/E9r PCR products were amplified from plants in all $\mathrm{F} 1$ populations, but no E4/A2r PCR products were observed (Table 4). 7H9F/AST-R, AST-F/AST-R, and AST-F/PCNA-F/5R3R PCR products were also amplified from plants in the F1 populations, but there were certain instances where resulting AST-F/AST-R PCR products did not match plant phenotype. Furthermore, SCAR marker phenotype association was confirmed for 7H9F/AST-R and AST-F/PCNA-F/5R3R when these were applied to F1 populations, but inconsistent genotyping results were observed for these two markers (data not shown). Therefore, E4/E9r and AST-F/PCNA-F/5R3R were considered as appropriate markers for use in PCNA MAS.

\section{Evaluation of SCARs using PCNA and non-PCNA progeny}

Non-PCNA progeny plants derived from a cross between 'Jamisi' (PVNA) and 'Sae-Fuji' (PVNA) and PCNA progeny plants from a cross between 'Maegawajiro' (PCNA) and 'Taishu' (PCNA) were evaluated using three markers, 7H9F/AST-R, AST-F/AST-R, and AST-F/ PCNA-F/5R3R, to select the minimum primer combination for selecting PCNA at seedling stage. AST-F/AST-R and 7H9F/AST-R amplified PCR bands (190 bp and 410 bp) specific to non-PCNA (Ast allele) only from the non-PCNA progeny. These markers did not amplify any specific band from the PCNA progeny, although there was one plant that showed a 410-bp band specific to non-PCNA by 7H9R/AST-R (Fig. 2A, B). The third marker AST-F/PCNA-F/5R3R amplified two PCR bands in a heterozygous state from all non-PCNA progeny, but amplified a PCNA-specific (ast allele) 350-bp band from all PCNA progeny except for one plant (Fig. 2C).

\section{Non-PCNA type offspring}

A. AST-F/AST-R

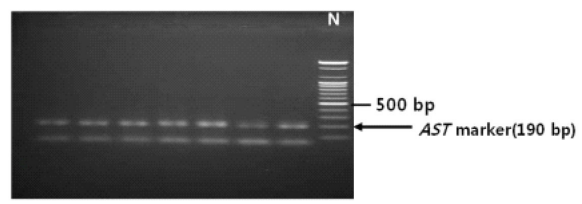

B. 7H9R/AST-R

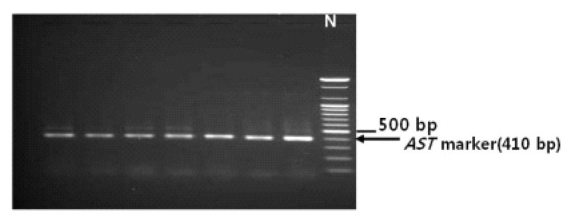

C. AST-F/PCNA-F/5R3R

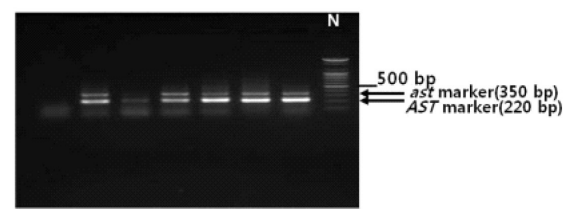

\section{PCNA type offspring}
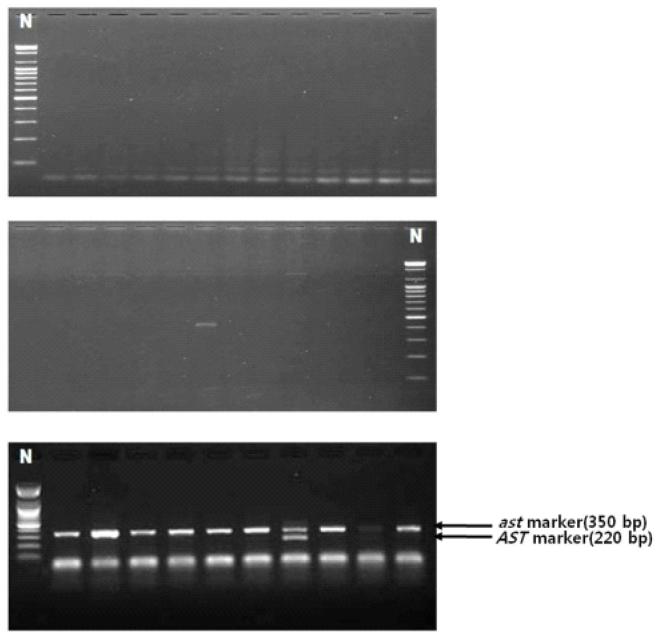

Fig. 2. Agarose gel image showing the segregation of the sequence characterized amplified region (SCAR) markers in breeding population of non-pollination-constant non-astringent (PCNA)-type offspring (I) and PCNA-type offspring (II), For AST-F/AST-R (A) and 7H9R/AST-R (B), the $A S T$-specific 190-bp and 410-bp fragment was present in all non-PCNA-type offspring, but absent in PCNA-type offspring, respectively. For a multiplex PCR by the primer pair AST-F/PCNA-F/5R3R (C), all PCNA offspring showed the ast-specific 350-bp fragment while non-PCNA-type offspring showed the $A S T$-specific 220-bp fragment.

$\mathrm{N}$ : 100-bp marker. 


\section{Evaluation of SCARs using germplasm accessions}

E4/E9r and AST-F/PCNA-F/5R3R markers were also evaluated for 82 cultivars and two breeding lines for which the astringency trait has been previously characterized. These 84 accessions included 31 PCNA, 21 PVNA, 11 PVA, 21 PCA types, and depending on the origin, two Chinese, one Italian, one Spanish, 32 Korean, and 59 Japanese accessions (Table 1). From the genotyping results of the two markers, we observed that there was no association of markers with phenotype for six accessions: 'Wasesaijo', 'Goseung-Tabegam', 'Gyeongsan-Bansi', 'Hiratanenashi', and 'Waseziya' for E4/E9R and 'Kaki Tipo' for AST-F/PCNA-F/5R3R. For the Korean PCA heirloom cultivars 'Goseung-Tabaegam' and 'GyeongsanBansi', the expected 2,200-bp PCR product specific for the Ast allele was not observed for E4/E9r, which implies that this marker possibly cannot be used for Korean PCA cultivars. Overall, the phenotype match rates of E4/E9r and AST-F/PCNA-F/5R3R markers were $94 \%$ and $99 \%$, respectively, indicating that AST-F/PCNA-F/5R3R is a more appropriate marker for selecting PCNA.

\section{Evaluation of marker applicability for MAS}

AST-F/PCNA-F/5R3R was integrated into a MAS program performed at the SPRI using segregating breeding populations. These populations comprised of a total of 609 progeny plants that were isolated from 2009 to 2012 from diverse crosses, including that between 'Youhou' (PCNA) and 'Taishu' (PCNA). As a result of MAS, 107 PCNA candidate plants (17.6\%) that displayed the marker result specific to the ast allele were isolated (Table 2). In an assessment of marker association with astringency phenotype, fruits from only 154 out of 609 plants could be evaluated, as the remaining plants did not survive, were too young to bear fruits, or displayed deformed or premature small fruits. Our results revealed that of the 154 analyzed plants, 33 PCA, 13 PCNA, 106 PVNA, and two PVA types were present, and marker-trait association was confirmed for all except three plants.

\section{DISCUSSION}

In the present study, we used five SCAR markers associated with astringency in persimmon fruit, namely E4/E9r, E4/A2r, 7H9F/AST-R, AST-F/AST-R, and AST-F/PCNA-F/5R3R, to improve the efficiency of PCNA-type persimmon breeding via MAS. To select the minimum primer combination for selecting PCNA at seedling stage, E4/E9r and AST-F/PCNA-F/5R3R were considered as appropriate markers for use in PCNA MAS. But Mitani et al. (2014) assessed use of SCAR markers $\mathrm{E} 4 / \mathrm{A} 2 \mathrm{r}$ and 7H9F/AST-R for selecting astringency type in segregating populations derived from crossing 'Taiten' with PCNA cultivars. However, no E4/A2r PCR products specific for the ast allele were observed despite using identical PCR conditions as previously described (Mitani et al. 2014). In addition, it is noteworthy that these markers can produce PCR products from plants in a segregating population derived from crossing with a Korean cultivar 'Cheongdo-Bansi' (Table 1), even though the markers originated from Japanese cultivars. This indicates that markers can be used in different ways for breeding programs that use Korean germplasm.

In conclusion, we confirmed that AST-F/PCNA-F/5R3R is the optimal SCAR marker for differentiating PCNA from non-PCNA germplasm accessions. Furthermore, our evaluation of progeny plants resulting from diverse crosses indicated that this marker can be used for MAS in sweet persimmon breeding programs.

\section{ACKNOWLEDGEMENTS}

This work was supported by a 2-Year Research Grant of Pusan National University.

\section{REFERENCES}

Ikeda I, Yamada M, Kurihara A. 1985. Inheritance of astringency in Japanese persimmon. J. Jpn. Soc. Hor. Sci. 54: 39-45.

Kanzaki S, Akagi T, Masuko T, Kimura M, Yamada M, Sato 
A, et al. 2010. SCAR markers for practical application of marker-assisted selection in Persimmon (Diospyros kaki Thunb.) breeding. J. Jpn. Soc. Hort. Sci. 79: 150-155.

Kanzaki S, Sato A, Yamada M, Utsunomiya N, Kitajima A, Ikegami A, et al. 2008. RFLP markers for the selection of pollination-constant and non-astringent (PCNA)-type persimmon and examination of the inheritance mode of the markers. J. Jpn. Soc. Hort. Sci. 77: 28-32.

Kanzaki S, Yamada M, Sato A, Mitani N, Ustunomiya N, Yonemori K. 2009. Conversion of RFLP markers for the selection of pollination-constant and non-astringent type persimmons (Diospyros kaki Thunb.) into PCR-based markers. J. Jpn. Soc. Hort. Sci 78: 68-73.

Kanzaki S, Yonemori K, Sugiura A, Sato A, Yamada M. 2001. Identification of molecular markers linked to the natural astringency-loss Japanese persimmon (Diospyros kaki Thunb.) fruit. J. Amer. Soc. Hort. Sci. 126: 51-55.

Kikuchi A. 1948. Pomology-part I. Yokendo, Tokyo, p. 34-400. Mitani N, Kono A, Yamada M, Sato A, Kobayahi S, Ban Y, et al. 2014. Practical marker-assisted selection using two SCAR markers for fruit astringency type in crosses of 'Taiten' $\times$ PCNA cultivars in persimmon breeding. Sci.
Hort. 170: 219-223.

Park YO, Jae HJ, Hwang JH, Kim SC, Lee YJ, Son BG, et al. 2013. Development of a SCAR marker for a selection of poillnation-constant non-astringent trait in persimmon (Diospyros Kaki Thunb.). J. Agric. Life Sci. 47: 65-47.

Tamura M, Tao R, Yonemori K, Utsunomiya N, Sugiura A. 1998. Ploidy level and genome size of several Diospyros species. J. Jpn. Soc. Hort. Sci. 67: 306-312.

Yamada M. 1993. Persimmon breeding in Japan. JARQ 27: 33-37.

Yamada M. 2005. Persimmon genetic resources and breeding in Japan. Acta Hort. 685: 51-64.

Yonemori K, Sugiura A, Sato A, Yamada M, Kanzaki S, 2003. Molecular marker for selecting pollination-constant non-astringent (PCNA) type persimmon at the juvenile stage. Acta Hort. 622: 189-203.

Yonemori, K, Sugiura, A, and M, Yamada. 2000. Persimmon genetics and breeding. Plant Breed. Rev. 19: 191-225.

Zhuang DH, Kitajima A, Ishida M, Sobajima Y. 1990. Chromosome numbers of Diospyros kaki cultivars. J. Jpn. Soc. Hort. Sci. 59: 289-297. 